\title{
Building communities for the exchange of learning objects: theoretical foundations and requirements
}

\author{
Rob Koper*, Kees Pannekeet, Maaike Hendriks \& Hans \\ Hummel \\ Educational Technology Expertise Center (OTEC), Open University of the Netherlands
}

In order to reduce overall costs of developing high-quality digital courses (including both the content, and the learning and teaching activities), the exchange of learning objects has been recognized as a promising solution. This article makes an inventory of the issues involved in the exchange of learning objects within a community. It explores some basic theories, models and specifications and provides a theoretical framework containing the functional and non-functional requirements to establish an exchange system in the educational field. Three levels of requirements are discussed. First, the non-functional requirements that deal with the technical conditions to make learning objects interoperable. Second, some basic use cases (activities) are identified that must be facilitated to enable the technical exchange of learning objects, e.g. searching and adapting the objects. Third, some basic use cases are identified that are required to establish the exchange of learning objects in a community, e.g. policy management, information and training. The implications of this framework are then discussed, including recommendations concerning the identification of reward systems, role changes and evaluation instruments.

\section{Introduction}

In online education there is a common need to reduce the workload of course developers, to increase the quality of courses and-more generally-to reduce costs. One way of attaining this objective is to stimulate extensive reuse of learning objects when developing new courses. A learning object is defined as: any entity, digital or non-digital, that can be used, reused, or referenced during technology-supported learning (IEEE LTSC, 2002). Reuse is defined as: the integration of a learning object created by someone else in the context of a new course (Koper, 2003). Reuse can happen at different levels in a so-called learning object economy (e.g., Campbell, 2003; Downes, 2003). At the first level, a person reuses something that is self-created. At

*Corresponding author. Educational Technology Expertise Center (OTEC), Open University of The Netherlands, PO Box 2690, 6401 DL Heerlen, The Netherlands. Email: rob.koper@ou.nl 
the second level, a person reuses something created by someone else within the boundaries of a specific community or organization. The third level of reuse is when a person buys something in the open market, e.g. a book from a publisher. The second level of reuse is the one that is mostly aimed at when reuse in education is discussed. We will refer to this as a 'learning objects exchange community'.

There is still a big gap to bridge between the worldwide need for reuse in education and actual reuse in practice. Thousands of learning objects are already available for sharing purposes (e.g., through systems like MERLOT, see Cafolla, 2003), but only a small portion is actually reused in educational practice. A course developer still has to cope with major problems when trying to find, retrieve, adapt or use materials that could be reused. For instance, in the context of Open Universities and eUniversities in Europe, we have experienced that the efforts required to reuse objects in most cases outweigh possible advantages. This is especially true when the objects are developed in different institutions. In many cases, course developers have decided that it is easier to (re-)create the materials themselves than reusing them from others.

To tackle these problems, we felt a need to look at the underlying basic principles and requirements for effective reuse in education. The basic question we had was: can we define a theoretical framework to describe the requirements for the development of a successful learning object exchange community?

This article presents the framework. It consists of a description of usable background theories, models and technologies and the set of use cases that capture the requirements for a learning object exchange community.

\section{Theoretical and technological building blocks}

\section{Self-organization theory}

Shaffer and Anundsen (1993) define a community as a dynamic whole that emerges when a group of people share common practices, are interdependent, make decisions jointly, identify themselves with something larger than the sum of their individual relationships and make a long-term commitment to the well-being (of their own, others' and the group as a whole). This vision is related to the principles of complexity theory (see Waldrop, 1992), more specifically to self-organization theory (e.g., Maturana \& Varela, 1992). This theory states that some characteristics of the social organization of communities emerge from the interactions of lower level agents. The social organization that emerges (e.g., grouping, specialisation of roles, coordination of actions, distribution of tasks and resources, conflict resolution, quality norms, and interaction standards) in its turn imposes behavioural constraints on the lower level agents by means of social objectives (Ferber, 1999). For instance, an important emergent property in communities with lasting participation is 'trust'. Trust is the expectation that arises within a community of regular, honest, and cooperative behaviour, based on commonly shared norms on the part of the members of the community (Fukuyama, 1995).

When establishing a self-organized system one has to set up certain mechanisms, like initial policies that reflect the purpose of the community and the social behavioural 
constraints (e.g., copyright, privacy, expected behaviour, grouping, user rights management) and mechanisms that facilitate interaction and allow policy change. Another important factor is the creation of first and second order feedback mechanisms. First order means that people in the community know what comparable others are doing or have done. This provides information for navigation and provides example behaviour within the community. Second order feedback is feedback about the emergent properties in the system: what is the performance of the community and how is it organized (Gilbert, 1995)? Self-organization research argues that a division of labour, with different activities performed simultaneously by (groups of) specialized individuals, is more efficient than a sequential execution of tasks by unspecialised individuals (Bonabeau et al., 1999). However, the specialization of roles among members can change when other needs arise. This implies that a person holds a specialized role in a community, but that the role can change when needed, according to some policy principles.

\section{Social exchange theory}

Social exchange theory provides a theoretical framework with guidelines to increase active participation and decrease lurking. This theory (Constant et al., 1994; Thibaut \& Kelly, 1959), derived from rational choice theory in economics, suggests that there is a relationship between a person's effect (satisfaction with a relationship) and his commitment to that relationship, i.e. his willingness to contribute and share knowledge. Social exchange theory argues that individuals evaluate alternative courses of action so that they get best value at lowest cost from any transaction completed. Literature (e.g., Hall, 2001) suggests four main reasons that could underlie the motivation and commitment of community members to share knowledge:

1. Personal need, or anticipated reciprocity: learner has a pre-existing expectation that he will receive actionable and useful information in return.

2. Reputation: learner feels he can improve his visibility and influence to others in the community, e.g. leading to more work or status in the future.

3. Altruism, or the perception of efficacy of the community in sharing knowledge as a 'public good', especially when contributions are seen as important, relevant and related to outcomes.

4. (Tangible) reward: learners negotiate to get some kind of more tangible asset (financial reward, bond, etc.) in return.

Likewise, others make distinctions between individual (personal need, reputation, reward) and interpersonal factors (altruism) (Deci \& Ryan, 1985), hard (e.g., access) and soft (e.g., satisfaction) rewards (Hall, 2001), quantitative and qualitative gain, or intrinsic and extrinsic factors (Hemetsberger, 2003). Many researchers warn against introducing (more tangible) extrinsic rewards as incentives, since they might destroy the motivation to share for the 'public good'. When knowledge is considered a public good (McLure Wasko \& Faraj, 2000), knowledge exchange is motivated by moral obligation and community interest (altruism) rather than by narrow self-interest 
(personal need, reputation). A public good is a commodity that can be provided only if group members contribute something towards its provision; however all persons may use it (Komorita \& Parks, 1995). Greater self-interest reduces knowledge sharing (Constant et al., 1994) and people are less likely to use collaborative technologies to share information perceived to be owned by the organization (Jarvenpaa \& Sensiper, 1998). Introducing tangible rewards in return for the provision of public goods promotes self-interested behaviour, reduces intrinsic motivation and destroys the public good. The danger is that individuals may appear to be contributing something, but what is not contributed is more significant. This would appear to be more significant when reward mechanisms are in operation (Von Krogh, 1998). Incentives for knowledge sharing should match the spirit of what is to be achieved (Sawyer et al., 2000).

Besides intrinsic and extrinsic factors that motivate individual community members to share knowledge, Hemetsberger (2003) identified two other key elements of exchange processes and relations in a community:

Common goals and values. Communities gather around a common interest, a passion (Kozinets, 1999). Values are important moderators for solidarity in relationships (Anderson et al., 1999).

Communal relationships. On a micro level, intimate communal ties can be distinguished (Rheingold, 2000). On a meso level there can be a web of personal relationships in cyberspace or trusting relationships between two or more partners (Grönroos, 1999).

All these elements of social exchange play a complex and often intertwined role in communities. The right combination of those elements can constitute a powerful mechanism for a self-sustaining system for the exchange and reuse of learning objects. All of them define the willingness (motivation) of the members to exchange learning objects in a community.

\section{Models for community building}

Revisiting Shaffer and Anundsen's definition of communities (1993), summarized above, the features attributed to individuals can be extended by considering qualities attributed to the group as a whole. Communities tend to be self-governed, selforganized and decentralized. Common goals, values and communal relationships are important moderators in forming communities. Communities have their own identity, which can change and evolve in time.

A community of practice $(\mathrm{CoP})$ is a group of practitioners in a certain field of expertise who share knowledge and experience. The group members typically possess different levels of experience and novices are supported to become expert members of the group through some guidance (or scaffolding) mechanisms (see, for example, Lave \& Wenger, 1991). Within a CoP, collaboration is stimulated; and the members of the community establish a group identity with common ideas about purpose and 
values (implemented in so-called community policies) that are shared by the group members. In a CoP, learning to become a (better) expert member is the major objective.

Wilson and Ryder (1998) characterize learning communities as follows:

1. they have distributed control;

2. there is commitment to the generation and sharing of new knowledge;

3. learning activities are flexible and negotiated;

4. community members are autonomous;

5. there is a high level of dialogue, interaction and collaboration; and

6. there is a shared goal, problem or project that brings common focus and incentives to work together.

When designing online communities, two aspects are of importance: usability and sociability. According to Preece (2000, pp. 26-27), software with good usability supports rapid learning, high skill retention, low error rates and high productivity. It is consistent, controllable and predictable, making it pleasant and effective to use. Paas and Firssova (2003) developed a research-based framework of methods for the evaluation of usability in web-based learning environments. Eight different attributes are identified: effectiveness, efficiency, learnability, memorability, flexibility, robustness, error minimization and satisfaction.

Sociability governs the social interactions in a community. It cannot be controlled directly, but it can be supported by carefully communicating the purpose and policies (values) of the community. Preece (2000, pp. 95-96) identifies several different policies that can be addressed in a community: joining or leaving requirements; bylaws; codes of practice for communication; rules for moderation; issues of privacy and trust; practices for distinguishing professionally contributed information; rules for copyright; and democracy and free speech in the community.

Palloff and Pratt (1999, p. 24) give a summary of the seven basic steps to follow when building a community. These steps can be considered as the sociability requirements to build successful learning object exchange communities:

1. clearly define the purpose of the group;

2. create a distinctive gathering place for the group;

3. promote effective leadership from within;

4. define norms (policies) and a clear code of conduct;

5. allow for a range of member roles;

6. allow and facilitate subgroups; and

7. allow members to resolve their own disputes.

\section{Interoperability specifications for learning objects}

The concept of technical reuse of learning objects has its foundation in the objectoriented approach within software engineering (e.g. Booch et al., 1999). In that domain, reusability is governed by certain general principles that can be applied to 
learning objects (Koper, 2003). Learning objects are technically reusable under the following four general conditions (the so-called non-functional requirements for exchange):

1. Optimal granularity. The object must be as small as possible without loosing its internal consistency (South \& Monson, 2001).

2. Encapsulation. The ideal learning object can stand on its own (encapsulated), have no side effects to e.g. dossiers of learners, enabling reuse without side effects (Hamel \& Ryan-Jones, 2002).

3. Abstraction. Reusable learning objects are abstracted towards the context of use (pedagogy, media, setting) as much as possible to allow for reuse within other pedagogical approaches, other settings and in other media (e.g., the reuse of paper resources in the web).

4. Interoperability. In order to be reusable within a community, a learning object must be available in an interoperable way, i.e. it must conform to the standards that are defined within the community.

A sensible approach to interoperability is to select and accept standards from the available open specifications (e.g. from IMS and IEEE) first and then to look at any further specifications that are needed to establish interoperability in the community. However, communities have to take care that the standards offer the functionality that they want. Too many current standards are too restricted from a pedagogical perspective or too complex for the restricted use of a certain community. Permanent monitoring and decisions about the standards (and versions of standards) to follow should be incorporated in any exchange community. We suggest considering the following interoperability standards for exchange communities (see Table 1).

There are several missing specifications in the field of binary resources (e.g., for simulations) and for most communication, search and collaboration services (although IMS Learning Design defines an initial set of services). One has to decide within a community how to deal with the missing specifications. Also one has to decide how to use the specification. Most specifications allow for further customisation or have many optional elements one has to choose from.

\section{Use cases for exchange}

One approach to capture functional requirements of the exchange community is to model so-called UML use cases (e.g., Fowler, 2000). Use cases are abstractions of scenarios in which the concrete behaviour of persons within a system, or using a system is described (Cockburn, 2001). A use case model contains use cases, actors and relationships (Armour \& Miller, 2001). Use cases (ellipses in diagrams) are sequences of actions required of the system, which it must be able to support if it is to function properly. Actors (stick figures in diagrams) are the persons or software agents that initiate the use cases, perform the use cases or benefit from the use cases. Relationships (lines in diagrams) link two elements to show how these interact. Derived from the theories and technologies described above, we modelled the use 
Table 1. Suggested use of interoperability specifications in exchange communities

\begin{tabular}{|c|c|c|}
\hline Interoperability of: & Advised & Other alternatives \\
\hline Non-binary resources & $\begin{array}{l}\text { XHTML (2003), using additional } \\
\text { (namespaced in) schemas for } \\
\text { formulas, images, etc. }\end{array}$ & $\begin{array}{l}\text { HTML or de facto standard } \\
\text { formats like MS-Word and } \\
\text { RTF.HTML }\end{array}$ \\
\hline Binary resources & $\begin{array}{l}\text { Depends on data type, e.g. PNG, } \\
\text { JPEG, MPEG, ... }\end{array}$ & $\begin{array}{l}\text { De facto standards, like Flash, } \\
\text { Java, gif, ... }\end{array}$ \\
\hline $\begin{array}{l}\text { Resource descriptions for } \\
\text { learning objects }\end{array}$ & $\begin{array}{l}\text { IEEE (LOM, 2003) with IMS- } \\
\text { LOM XML binding (XML, } \\
\text { 2003) }\end{array}$ & $\begin{array}{l}\text { Dublin core metadata (with } \\
\text { educational extensions) in RDF/ } \\
\text { XML binding; or OWL web } \\
\text { ontology language (OWL) }\end{array}$ \\
\hline $\begin{array}{l}\text { Resource descriptions for } \\
\text { all other type of learning } \\
\text { objects }\end{array}$ & $\begin{array}{l}\text { Dublin core (DC, } 2003 \text { ) } \\
\text { metadata in } \mathrm{RDF} / \mathrm{XML} \text { binding }\end{array}$ & $\begin{array}{l}\text { LOM or any library format; or } \\
\text { OWL web ontology language }\end{array}$ \\
\hline Packages & IMS content package $(\mathrm{CP}, 2003)$ & $\begin{array}{l}\text { ZIP files without predefined } \\
\text { structure }\end{array}$ \\
\hline $\begin{array}{l}\text { Units of learning (e.g. } \\
\text { course) }\end{array}$ & IMS learning design (LD, 2003) & $\begin{array}{l}\text { IMS Content Package, or ADL } \\
\text { (SCORM, 2003) }\end{array}$ \\
\hline Testing & $\begin{array}{l}\text { IMS question and test } \\
\text { interoperability specification } \\
\text { (QTI, 2003) }\end{array}$ & $\begin{array}{l}\text { Proprietary testing software (e.g. } \\
\text { in LMSs). }\end{array}$ \\
\hline Learner Data & $\begin{array}{l}\text { IMS learner information package } \\
\text { (LIP, 2003) }\end{array}$ & Locally agreed learner dossier \\
\hline
\end{tabular}

case diagram represented in Figure 1 to capture major functional requirements. In the next paragraphs we will explain the use case model.

\section{Actors}

Derived from the self-organization theory, we identify one type of actor that can have different roles. This actor is called a 'member' and is defined as any person who is actually or potentially creating learning objects within the domain of the exchange community. A member can be an individual or a group of individuals in any formal or informal organization. Several roles for members can be specified, e.g. the producer, (re-)user, and group moderator. These types of roles search, use and add learning objects. We have drawn a specific role, called the community facilitator, who is responsible for communal aspects, like information, promotion, editing of the policies, monitoring and increase of usability. Note that these roles are assigned to persons, and the same person can have multiple roles. The use case 'change organization structure' is responsible for the definition and allocation of roles and system rights. Like any rule in the system, this process is governed by explicitly defined and collectively maintained community policies.

Having discussed (first level) requirements for technological interoperability in the previous section, we will now first describe the necessary (second level) actions (in the 


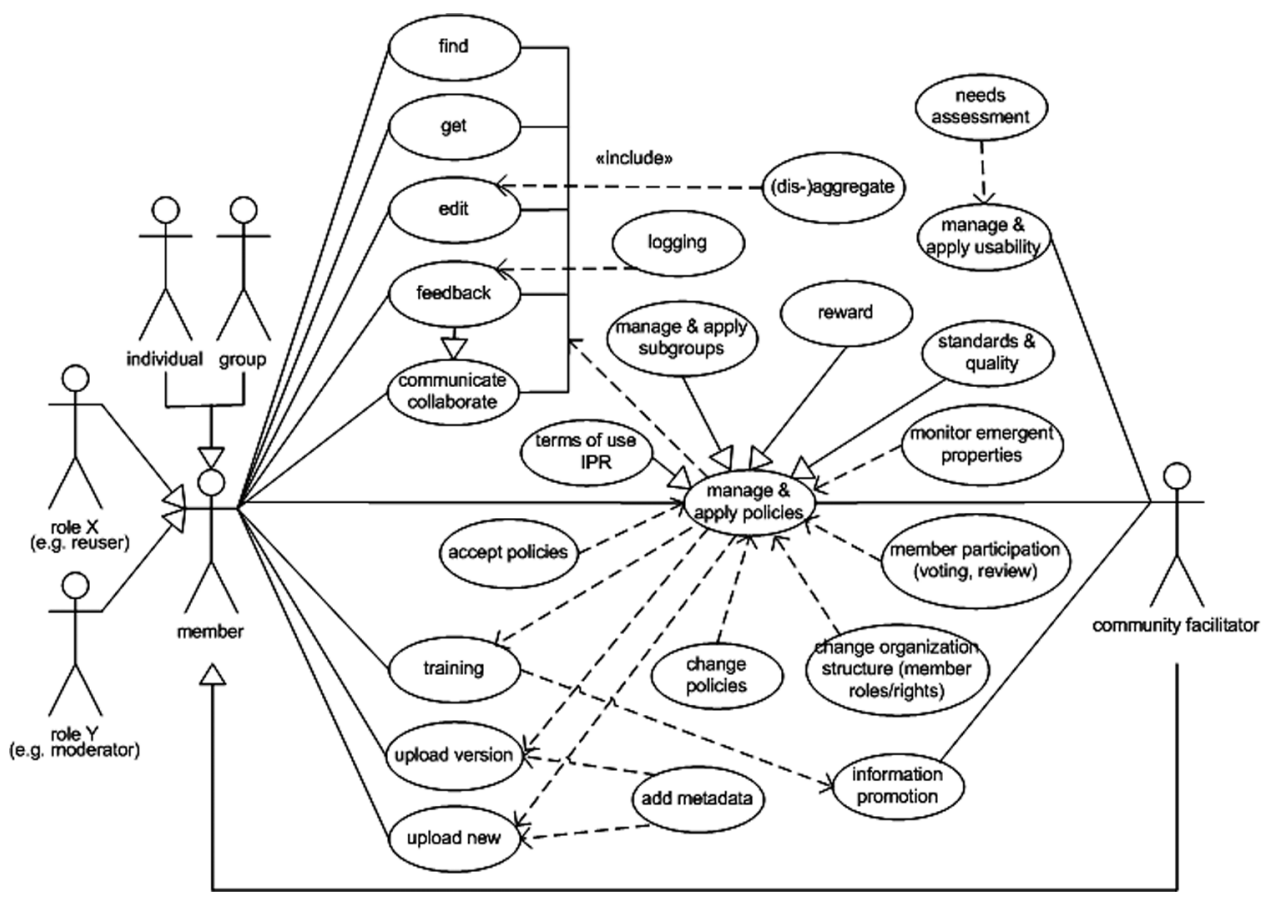

Figure 1. Use cases in a learning object exchange community (UML use case diagram, all dotted lines are $<<$ include $>>$ dependencies)

form of use cases) that enable the exchange of learning objects, followed by some basic (third level) actions that are required to establish exchange in the context of a community.

\section{Use cases to realise exchange from a technological perspective}

Find, get, edit and (dis-) aggregate. To be able to search and find a learning object, the common idea is that a search engine can search through the metadata descriptors (or full text index) of the objects. To get access to a learning object, the object itself should be available for a certain price or license. One way of getting access to an object is through an URI reference (for example MERLOT, see Caloffa, 2003). Another approach is to download a copy. Users may want to adapt a learning object to the specific local context of use. In order to allow for this process, the learning object must be loaded into a suitable local or remote editing tool. This is only possible when the source of the learning object is available and when the source is in a format that available tools support. Part of the editing process is to aggregate a collection of learning objects towards its aim: the building of a course. Aggregation can be done in several ways: through a collection of links, through a collection of physical objects or a combination of both. Typically a specification like IMS Content Packaging, 
as used by IMS Learning Design, will be used to for the aggregation of links and physical files.

Upload version, upload new and add metadata. One must be able to upload new or adapted learning objects. This can be done with standard available web protocols (e.g. FTP) or even with email.

Feedback and logging. Feedback is needed to support self-organization, adequate object selection, quality control and navigation. It is important that users provide feedback about the use of a certain learning object, provide tips for other users and assess its quality.

Communicate and collaborate. Besides feedback, other types of communication and collaboration are needed for communities to share experiences. One must be able to communicate members' profiles, including information about the member's role and past performance in the community. This provides a means to look at a member's background and reputation, e.g. a feedback provider, to judge the relevance and quality of the contribution. It also provides information, e.g. an email address, for further (subgroup or private) discussion.

Meta-comments about the use of learning objects or the community facilities are required more generally, allowing the exchange of knowledge and experience at a more generic level (e.g., How do we reuse materials in our organization?) and supporting the establishment of a community of practice (Lave \& Wenger, 1991). A typical approach in an online community is to organize moderated, asynchronous discussion forums connected to synchronous events like conferences, workshops, or invited addresses.

Tools that support collaboration between members who have some common interest and will typically establish a subgroup in the community are shared workspaces (e.g., BSCW, 2003) and synchronous collaboration tools (e.g., shared whiteboard, version controlled joint editing of documents).

\section{Use cases to realize exchange in a community}

Needs assessment. The needs of the members must be assessed at a regular basis, to improve the usability and the overall functionality of the exchange system.

Manage and apply policies. One of the central use cases involves managing and applying policies. As the name suggests it contains three elements: keeping record of the policies in the community; providing mechanisms to apply these policies in the community; and providing policy-regulated mechanisms to change these policies. The policies include aspects as: intellectual property rights; terms of use; 
membership; joining or leaving requirements; the reward system; learning technology standards to be used in the community; quality control mechanisms; regulations for member participation (assessments, voting, peer-review); and regulations for subgroups and role changes (e.g., facilitator). To apply the policies, members must formally agree with the policies. The concrete regulations a person has to agree upon can differ depending on the user role and responsibilities. There must be a control mechanism that makes members behave according to the policies. This control mechanism can be implemented by assigning responsibilities to a member role, by establishing some social control mechanisms and/or a by technological measures, e.g., by setting user rights. There are several reasons to change policies, one of which is the monitoring of the emergent properties. When the frequency of exchange is low, exchanged learning objects have poor quality or, for example, there are systematic conflicts between participants (lack of trust), this can trigger a change in policies. Changing policies is one of the major control instruments in self-organized systems.

Different policy aspects (quality, review) were already discussed in the theoretical part of this article. Two more issues will be addressed here: the intellectual property rights and the user roles/rights. In the field of digital rights management (DRM), currently two models are in force. From the recording and movie industries, the model of 'Enforced DRM' is promoted. The model of 'Attributed DRM' is promoted by educational organizations worldwide and is supported by the IEEE (DR, 2003). In this model, which supports current practices, usage of material is permitted either by payment or by simply attributing through layers that are added to the material (metadata or digital rights expression language-DREL). From an organizational point of view it is advisable to put some people in charge of tracking the information on the fast evolving fields of DRM and the implementation of DRM-policies. Creating a greater 'digital rights' awareness amongst colleagues should also part of their job (see also CEN/ISSS, 2003).

Another mechanism to control the monitoring of policies in an electronic environment is by setting user roles and rights. When a member's role is changing, the assigned user rights can be set automatically in the system. These rights pertain to access to certain functions and data, and the ability to read, edit and upload. For instance, setting the rights for a community facilitator could pertain to editing the policies. Given the fact that policies are the major control mechanisms for selforganization and that user rights can be seen as an implementation of the policies in electronic environments, it can be argued that the major control mechanism in an learning object exchange community is the definition and setting of user roles and connected rights.

Information, promotion and training. As stated in the section on background theories, the fact that a good exchange system is available does not guarantee its usage. For an organization the possibilities of sharing and reuse of resources should first and foremost lead to cost-reduction. Such benefits are not always obvious to teachers who 
have to do the job. If this change in (working) attitude is not managed and guided adequately, organizations will face the danger of reluctant teachers who will do anything to undermine these changes (McNaught, 2003). This is a difficult motivation issue, as explained by social exchange theory. Given this problem, it is necessary to give special attention to activities like:

1. attracting new members, mainly by communicating the purpose and policies (e.g., the reward system);

2. promoting use within the existing membership (e.g., promoting use of particular learning objects) and providing facilities to advertise personal productions;

3. providing training facilities for new and existing members and overcoming barriers at the personal level, like the 'not-invented-here' syndrome or the 'free-rider' effect.

Improving collaboration between actors is one of the most important challenges in establishing a learning object exchange community. To make a start with effective collaboration, a number of basic conditions need to be taken care of, including a common organizational structure, common tools for employers and common goals (Wetterling \& Collis, 2003). A number of issues need to be addressed, recognized and guided alongside these basic conditions. For example, will a teacher be able to preserve his own teaching style, or does he need to conform to that of 'the group'? Will teachers be given enough time, support and guidance in order to make the (work) attitude change? It will be necessary for the organization to point out to the teachers that the challenge of reuse is exciting and not stressful. For some, this will require a change of attitude.

With respect to the not-invented-here-syndrome, people still tend to think that something made elsewhere cannot be as good as that which is homemade. It may prove to be helpful for authors/developers to explain what they have made and how they use it (e.g., SoURCE, 2003).

'Free-riding' (Olson, 1965) or 'lurking' occurs when people never contribute or cease to contribute to a community. In most of these cases, knowledge is not acknowledged as a public good that is the responsibility of a group, but becomes a good that can be taken and used. The community thus suffers from a social dilemma. Members of a community need to be motivated to contribute. As social exchange theory states, people make comparisons between two alternatives and select the alternative most beneficial for themselves, ensuring the lowest costs (Thibaut \& Kelly, 1959). Empirical evidence has proved that when group size increases, the proportion of volunteers that contribute decreases (Fischer \& Ackerman, 1998). While this might be true for communities in environments other than the web, there is also empirical evidence that 'virtual communities' behave differently in this respect (Hemetsberger, 2003). The LINUX and Apache open-source communities are leading examples of communities that are successful in enabling a relatively large number of members to share knowledge and contribute to a growing array of software-products. These communities also substantiate research findings that communities should always gather around a common interest or goal (Kozinets, 1999). 
Manage usability. In the community it is necessary to set up mechanisms to monitor the usability of the system. A needs analysis can identify usability problems, but other approaches are also possible, such as a facility that counts errors or frequency of use of certain facilities. Actions to increase usability almost always involve some (re-)programming activities and (re-)design of the user-interface. It is important to have capacity available to create the improvements needed.

\section{Conclusion}

In this article we presented a framework that summarizes the functional and nonfunctional requirements for the exchange of learning objects in a community. The framework is based on self-organization theory, social-exchange theory, community building models, and interoperability specifications for learning objects. The nonfunctional requirements are presented in Table 1, and the functional requirements are captured in a use case represented in Figure 1. We propose recommendations on three consecutive levels: to use open standards and specifications to code, aggregate and identify the different learning objects; to build upon certain use cases to enable the actual exchange of the learning objects at a technological level; and to establish a community of practice based on self-organization principles to create an effective environment for exchange. Above and beyond these recommendations, the most critical aspect in self-organized systems is to establish interactions between participants that are governed according to some rules, or policies as they are called in this article. These rules are comparable with the rules of games like chess, laws in a society or by-laws in an association.

The article only provides some suggestions to establish these rules or policies, but one line of future research should focus on the optimization of policies to establish successful exchange systems. For instance, an experimental comparison of certain reward policies in a community might provide some useful insights to this optimization problem. Working in communities might also be intrinsically rewarding. Submitting a learning object, then 'experiencing' peer reviews and working further towards a final version of the object might work in ways similar to the reviewing process that guides the writing of journal articles. In domains like economics and social psychology, successful reward systems have appeared to be successfully applied, but we still have to search for the adequate combinations of intrinsic and extrinsic rewards that will establish a successful exchange community in the educational arena.

Besides the reward system the specific organization, e.g. the roles and responsibilities, can be the object of a second line of more detailed research. What type of organizational structure works best and under what conditions? For instance, there is a difference between the establishment of an exchange system within an existing organization (e.g., university, department, eUniversity, company) based on the idea that only persons that work for the organisation will share there resources, as opposed to an exchange system with an open admission that can be used by everybody who wants to and is able to use it.

As a third line of future research we envisage developing an evaluation instrument based on the requirements framework provided in this article. With such an instrument 
we will be able to evaluate and compare concretely implemented initiatives and provide suggestions for their improvement. Such an instrument would establish a minimal set of requirements, and weigh the different requirements for learning object exchange environments. And last but not least, it would provide a starting point for the development of new exchange communities.

Exchanging learning objects within the context of communities seems a potential step towards an affordable e-learning future. Because of the potential quality and cost impact upon education, it is extremely important to continue further research, development and implementation this area. This research should combine a further definition of necessary standards, the development of sound, specific models and policies for exchange, and the building of facilitative tools and infrastructures that enable the exchange of learning objects in communities.

\section{References}

Anderson, W., Challagalla, G. \& McFarland, R. (1999) Anatomy of exchange, fournal of Marketing Theory and Practice Fall, 8-19.

Armour, F. \& Miller, G. (2001) Advanced use case modeling (Upper Saddle River, NJ, AddisonWesley).

Bonabeau, E., Dorigo, M. \& Theraulaz, G. (1999) Introduction, in: Swarm intelligence (Oxford, Oxford University Press).

Booch, G., Rumbaugh, J. \& Jacobson, I. (1999) The unified modeling language user guide (Reading, Addison-Wesley).

BSCW (2003) Basic support for cooperative work. Available online: http://orgwis.gmd.de/projects/ $\mathrm{BSCW} /$ (accessed 25 November 2003).

Cafolla, R. (2003) Project MERLOT: bringing peer review to web-based educational resources Available online: http://www.aace.org/conf/site/pt3/paper_3008_721.pdf (accessed 25 November 2003).

Campbell, L. (2003) Engaging with the learning object economy, in: A. Littlejohn (Ed.) Reusing online resources: a sustainable approach to e-Learning (London, Kogan Page).

CEN/ISSS (2003) European committee for standardization. Available online: http://www.cenorm.be/ cenorm/index.htm (accessed 25 November 2003).

Cockburn, A. (2001) Writing effective use cases (Boston, MA, Addison-Wesley).

Constant, D., Kiesler, S. \& Sproull, L. (1994) What is mine is ours, or is it?, Information Systems Research, 5(4), 400-422.

CP (2003) IMS Content Packaging. Available online: http://www.imsglobal.org/content/ packaging/index.cfm (accessed 25 November 2003).

DC (2003) Dublin core metadata initiative. Available online: http://dublincore.org/ (accessed 25 November 2003).

Deci, E. \& Ryan, R. (1985) Intrinsic motivation and self-determination in human behavior (New York, Plenum Press).

Downes, S. (2003) Design and reusability of learning objects in an academic context: a new economy of education?, USDLA fournal, 17(1). Available online: http://www.usdla.org/html/ journal/JAN03_Issue/article01.html (accessed 25 November 2003).

DR (2003) IEEE learning technology standardization committee WG4 digital rights expression language. Available online: http://ltsc.ieee.org/wg4/DREL_relevant_standards_survey-v4.doc (accessed 25 November 2003).

Ferber, J. (1999) Multi-agent systems (Reading, Addison-Wesley). 
Fischer, R. S. \& Ackerman (1998) The effects of recognition and group need on volunteering: a social norm perspective, fournal of Consumer Research, 25(December), 262-275.

Fowler, M. (2000) UML distilled, 2nd edn (Upper Saddle River, NJ, Addison-Wesley).

Fukuyama, F. (1995) Trust (New York, Simon \& Schuster).

Gilbert, N. (1995) Emergence in social simulation, in: N. Gilbert \& R. Conte (Eds) Autonomous societies: the computer simulation of social life (London, UCL Press), 144-156.

Grönroos, C. (1999) Relationship marketing: challenges for the organization, fournal of Business Research, 46, 327-335.

Hall, H. (2001) Social exchanges for knowledge exchange Paper presented at Managing knowledge: conversations and critiques, University of Leicester Management Centre, 10-11 April 2001.

Hamel, C. \& Ryan-Jones, D. (2002) Designing instruction with larning objects, International Fournal of Educational Technology, 3(1). Available online: http://www.ao.uiuc.edu/ijet/v3n1/ hamel/index.html (accessed 25 November 2003).

Hemetsberger, A. (2003) Fostering cooperation on the Internet: social exchange processes in innovative virtual consumer communities. Available online: http://tsc.ieee.org/wg12/files/ LOM_1484_12_1_v1_Final_Draft.pdf (accessed 25 November 2003).

IEEE LTSC (2002) IEEE learning technology standardization committee draft standard for learning object metadata, version 6.4. Available online: http://ltsc.ieee.org/doc/wg12/LOM_wd6_4.pdf (accessed 25 November 2003).

Jarvenpaa, S. \& Sensiper, S. (1998) The role of tacit knowledge in group innovation, California Management Review, 40(3), 112-132.

Komorita, S. \& Parks, C. (1995) Interpersonal relations: mixed-motive interaction, Annual Review of Psychology, 46, 183-207.

Koper, E. (2003) Combining reusable learning resources and services with pedagogical purposeful UOLs, in: A. Littlejohn (Ed.) Reusing online resources: a sustainable approach to e-Learning (London, Kogan Page), 46-59.

Kozinets, R. (1999) E-tribalized marketing? The strategic implications of virtual communities on consumption, European Management fournal, 17(3), 252-264.

Lave, J. \& Wenger, E. (1991) Situated learning: legitimate peripheral participation (Cambridge, Cambridge University Press).

LD (2003) IMS learning design specification. Available online: http://www.imsglobal.org/ learningdesign/index.cfm (accessed 25 November 2003).

LIP (2003) IMS learner information package specification. Available online: http://www.imsglobal.org/profiles/index.cfm (accessed 25 November 2003).

LOM (2003) IEEE learning technology standardization committee WG12 learning object metadata. Available online: http://tsc.iee.org/wg12/index.html (accessed 25 November 2003).

Maturana, H. \& Varela, F. (1992) The tree of knowledge: the biological roots of human understanding, revised edition (Boston, MA, Shambhala/New Science Press).

McLure Wasko, M. \& Faraj, S. (2000) It is what one does: why people participate and help others in electronic communities of practice, fournal of Strategic Information Systems, 9, 155173.

McNaught, C. (2003) Identifying the complexity of factors in the sharing and reuse of resources, in: A. Littlejohn (Ed.) Reusing online resources: a sustainable approach to e-Learning (London, Kogan Page).

MERLOT (2003) Peer review of MERLOT learning materials. Available online: http:/taste.merlot.org/ projects/peer_review/ (accessed 25 November 2003).

Olsen, M. (1965) The logic of collective action (Cambridge, MA, Harvard University Press).

Paas, F. \& Firssova, O. (2003) Usability evaluation of integrated e-learning, in: W. Jochems, J. Van Merriënboer \& E. Koper (Eds) Integrated eLearning (London, RoutledgeFalmer).

Palloff, R. \& Pratt, K. (1999) Building learning communities in cyberspace, (San Francisco, CA, Jossey-Bass).

Preece, J. (2000) Online communities: designing usability, supporting sociability (Chichester, Wiley). 
QTI (2003) IMS question E test interoperability specification. Available online: http://www.imsglobal.org/question/index.cfm (accessed 25 November 2003).

Rheingold, H. (2000) The virtual community: homesteading on the electronic frontier, revised edition (Cambridge, MA, MIT Press).

Sawyer, S., Eschenfelder, K. \& Hexkman, R. (2000) Knowledge markets: cooperation among distributed technical specialists, in: T. Srikantaiah \& M. Koenig (Eds) Knowledge management for the information professional (Medford, NJ, Information Today).

SCORM (2003) Advanced distributed learning. Sharable content object reference model. Available online: http://www.adlnet.org/index.cfm?fuseaction=scormabt (accessed 25 November 2003).

Shaffer, C. \& Anundsen, K. (1993) Creating community anywhere (New York, Perigee Books).

SoURCE (2003) SoURCE: software use, re-use \& customisation in education. Available online: http://www.source.ac.uk/ (accessed 25 November 2003).

South, J. \& Monson, D. (2001) A university wide system for creating, capturing and delivering learning objects. Available online: http://reusability.org/read/chapters/south.doc (accessed 25 November 2003).

Thibaut, J. \& Kelly, H. (1959) The social psychology of groups (New York, Wiley).

Von Krogh, G. (1998) Care in knowledge creation, California Management Review, 40(3), 13-153.

Waldrop, M. (1992) Complexity: the emerging science at the edge of chaos (New York, Simon \& Schuster).

Wetterling, J. \& Collis, B. (2003) Sharing and re-use of learning resources across a trans-national network, in: A. Littlejohn (Ed.) Reusing online resources: a sustainable approach to e-Learning (London, Kogan Page).

Wilson, B. \& Ryder, M. (1998) Distributed learning communities: an alternative to designed instructional systems, paper submitted to Educational Technology Research and Development.

XHTML (2003) Extensible hypertext markup language. Available online: http://www.w3c.org/ MarkUp/ (accessed 25 November 2003).

XML (2003) Extensible markup language. Available online: http://www.w3c.org/XML/ (accessed 25 November 2003). 